\title{
In-hospital and out-of-hospital stroke in patients with COVID-19: two different diseases?
}

\author{
Ludovico Ciolli ${ }^{1,2}$ - Veronica Righi ${ }^{2} \cdot$ Gabriele Vandelli $^{1,2} \cdot$ Laura Giacobazzi $^{1,2} \cdot$ Niccolò Biagioli $^{2}$. \\ Donato Marzullo ${ }^{2}$. Laura Vandelli ${ }^{1}$. Francesca Rosafio ${ }^{1}$ - Giulia Vinceti ${ }^{2}$. Stefania Maffei ${ }^{1}$. Livio Picchetto ${ }^{1}$. \\ Maria Luisa Dell'Acqua ${ }^{1}$ - Giuseppe Maria Borzi ${ }^{1}$ - Riccardo Ricceri ${ }^{1}$ - Guido Bigliardi ${ }^{1}$ - Stefano Meletti ${ }^{1,2}$
}

Received: 23 September 2021 / Accepted: 3 December 2021 / Published online: 22 January 2022

(c) Fondazione Società Italiana di Neurologia 2021

\begin{abstract}
Background Ischemic stroke is a known complication of COVID-19. It may have a different pathogenesis and worse outcome compared to stroke in patients without COVID-19. Furthermore, patients with COVID-19 and out-of-hospital stroke onset might have different characteristics compared to patients with COVID-19 and in-hospital stroke onset. The aim of our study was to analyze the characteristics of patients with stroke with and without COVID-19 and of patients with COVID-19 with in-hospital and out-of-hospital stroke.

Methods We performed a retrospective study of all consecutive patients admitted to our hospital with ischemic stroke between October 2020 and February 2021. We compared functional outcome, lab test, demographic, and clinical characteristics between patients with or without COVID-19. We performed a sub-analysis comparing patients with COVID-19 and in-hospital and out-of-hospital stroke onset.

Results We included in the final analysis 137 patients of whom 26 with COVID-19. Half (13) had out-of-hospital stroke and half in-hospital stroke onset. Overall, patients with COVID-19 had higher mortality compared to the control group (27\% vs $9 \%, p: 0.02)$, and non-significantly lower rate of good functional outcome (50\% vs 63\%, $p$ : 0.22). Patients with COVID-19 and out-of-hospital stroke had higher rate of good functional outcome (69\% vs 39\%, $p$ : 0.05), higher lymphocyte count, and lower D-dimer compared with patients with in-hospital stroke onset.

Conclusions Patients with stroke and COVID-19 had higher mortality compared to patients without COVID-19. Among patients with COVID-19 those with out-of-hospital stroke had better outcome and fewer blood test abnormalities compared to patients with in-hospital stroke.
\end{abstract}

Keywords COVID-19 $\cdot$ SARS-CoV2 $\cdot$ Ischemic stroke $\cdot$ Coagulopathy

\section{Introduction}

Ischemic stroke is a known complication of COVID-19 [1, 2]. According to a recent metanalysis up to $1.5 \%$ of patients with COVID-19 develops stroke [3]. Notably, the incidence of thrombotic complications appears higher in COVID-19

Ludovico Ciolli

lud.ciolli@gmail.com

1 Stroke Unit, Neurology Unit, Department of Neuroscience, Ospedale Civile Baggiovara - Azienda Ospedaliera Universitaria di Modena, Modena, Italy

2 Department of Biomedical, Metabolic and Neural Sciences, University of Modena and Reggio Emilia, Modena, Italy compared with other common respiratory infections [4]. Thus, COVID-19 might directly cause stroke in a subgroup of patients. Different mechanisms, such as COVID19-related hypercoagulability or endoteliitis [5], have been hypothesized. Patients with stroke and concomitant COVID19 , in particular those with cryptogenic stroke, seem to fare a worse outcome compared to patients with stroke without COVID-19 [6, 7]. They also have higher rate of complications and laboratory test abnormalities [7]. Many of the patients included in the published series were already hospitalized for COVID-19 when they developed stroke; these patients might differ from patients with COVID-19 and outof-hospital stroke onset with mild or no COVID-19-related symptoms. In such patients, SARS-CoV2 infection might 
not have an important role in the pathogenesis of stroke and have lower impact on the final outcome [8].

The aim of our study was to analyze the characteristics of patients with stroke with and without COVID-19 admitted to our hospital. We also performed a subgroup analysis comparing patients with COVID-19 and in-hospital and outof-hospital stroke onset.

\section{Materials and methods}

We performed a retrospective study of all consecutive patients admitted to our hospital with COVID-19 and ischemic stroke between October 2020 and February 2021 and compared them with stroke patients without COVID19 (control group) admitted to our stroke unit in the same period. The Modena University Hospital is an academic hubcenter for all emergencies and stroke of the Modena province (around 700.000 inhabitants) and is a second level stroke center for endovascular reperfusion treatments also for the Reggio-Emilia province (around 350.000 inhabitants).

We excluded (1) patients functionally dependent prior to the stroke/COVID-19 infection according to a modified Rankin scale $(\mathrm{mRS})>2$. We excluded these patients because the main aim of the study was to evaluate differences in functional outcome between patients with and without COVID-19; (2) patients with unknown 90-days functional outcome; (3) and patients that developed COVID-19 after stroke onset.

COVID-19 was diagnosed with a molecular nasopharyngeal swab test performed in the emergency department in all the patients admitted to our hospital. The swab test was repeated after $48 \mathrm{~h}$ and every 7 days thereafter. Patients were considered to have stroke and COVID-19 if they had a known active infection before stroke or if COVID-19 was diagnosed in the emergency department in patients presenting with acute ischemic stroke. Patients with COVID-19 were further divided according to hospitalization status at stroke onset. Patients already hospitalized because of COVID-19 infection at stroke onset were considered to have in-hospital stroke onset. Out-of-hospital stroke onset was defined if stroke occurred outside the hospital, in patients with known mild or asymptomatic SARS-CoV2 infection or in patients in whom the infection was diagnosed in the emergency department.

\section{Outcome measures}

The primary outcome was 90 days good functional outcome according to the mRS. The outcome was defined good if mRS was 0 to 2 and poor if mRS was 3 to 6 . We also analyzed the mortality rate. The mRS was assessed in our outpatient clinic or with a phone call by our certified stroke doctors. We compared demographic characteristics, cardiovascular comorbidities, routine blood tests, presence of large vessel occlusion (defined as occlusion of internal carotid artery, middle cerebral artery M1 and M2, vertebral or basilar artery), National Institute of Health Stroke Scale (NIHSS) at admission, and rate of hemorrhagic transformation on $24-48 \mathrm{~h}$ control CT, evaluated using neuroradiological reports. Stroke etiology was defined according to TOAST classification [9], but we differentiated embolic stroke of undetermined source (ESUS) from cryptogenic stroke. In the former, a comprehensive etiological study was performed, including prolonged EKG monitoring, echocardiography, and extracranial vessel imaging, in the latter, the study was incomplete.

We also analyzed the rate of intravenous thrombolysis (IVT) and endovascular thrombectomy (EVT), using data from The Italian Registry of Endovascular Treatment in Acute Stroke (REI) and local database of the Safe Implementation of Thrombolysis in Stroke-International Stroke Thrombolysis Register (SITS-ISTR). Finally, we evaluated the rate of respiratory failure needing ventilation (noninvasive or invasive mechanical ventilation) and the rate of thrombotic complications such as pulmonary embolism, deep vein thrombosis, or arterial ischemic events. We also analyzed the predictor of poor functional outcome in the COVID-19 and control groups.

We performed a subgroup analysis, comparing patients with stroke and COVID-19 with out-of-hospital and in-hospital stroke onset. A comparison was made between patients in these subgroups and between each subgroup and the control group of patients with stroke without COVID-19.

\section{Statistical analysis}

Variables are presented as absolute number and percentage or median and interquartile range (IQR). Categorical variables were analyzed with X2 or Fischer's exact test, whereas continuous variables were analyzed using the Mann-Whitney $U$-test. To assess the predictor of poor functional outcome, we performed a univariate regression analysis and implemented baseline characteristics associated with a $p<0.05$ in the univariate analysis and those judged clinically relevant into a multivariate analysis. Pearson's collinearity test was performed to exclude collinear variables. A $p$ value $<0.05$ was considered statistically significant. All statistical analyses were carried out using SPSS for Windows, version 21 (SPSS Inc., Chicago, IL, USA).

\section{Results}

We screened 151 patients for inclusion: 10 were excluded because of pre-stroke mRS $>2$ and 4 because of unknown 90 days outcome. None developed COVID-19 after stroke 
onset. Of the 137 patients included, 26 (19\%) had COVID19,13 of them (50\%) had out-of-hospital, and $13(50 \%)$ inhospital stroke onset.

\section{Comparison between SARS-CoV2 positive and negative patients}

The differences between the 2 groups are summarized in Table 1. The rate of 90 days good functional outcome was not significantly lower among COVID-19 patients (mRS $0-250 \%$ vs $63 \%, p$ : 0.22 ). However, they had a significantly higher mortality rate (27\% vs $9 \%, p: 0.02)$ (Fig. 1). COVID19 patients were not significantly younger compared to the control group (median 70 years old IQR 56.0-79.5 vs 75 IQR 65.0-82.0, $p$ : 0.19). Between-groups comparison showed that cryptogenic stroke was more common among COVID-19related strokes, whereas atheroembolic and lacunar strokes were non significantly more common in the control group. We did not find significant differences concerning cerebrovascular risk factors. Patients with COVID-19 less commonly were treated with IVT or EVT ( $27 \%$ vs $59 \% p$ : 0,02$)$, more frequently needed mechanical ventilation ( $42 \%$ vs $3 \%, p<0.01$ ), and more commonly developed thrombotic complications. The rate of hemorrhagic transformation was similar. COVID-19 patients had lower lymphocyte count and higher CRP, D-dimer, INR, and fibrinogen levels (see Table 1).

\section{Predictors of unfavorable outcome}

Among COVID-19 patients, at univariate analysis (Table 2), higher NIHSS, glycaemia, and D-dimer and lower lymphocytic count were predictors of poor outcome; none of these factors retained significance at multivariate analysis. In-hospital stroke was also associated with a trend for unfavorable outcome at univariate analysis (OR: 5.06, 95\% CI 0.96-26.78).

Among COVID-19 negative patients (see supplementary material table S1) higher age, NIHSS, CRP and glycaemia at stroke onset and presence of atrial fibrillation and diabetes mellitus were associated with poor outcome at univariate analysis. Higher age and glycaemia were confirmed at multivariate analysis.

\section{In-hospital vs out-of-hospital stroke onset in patients with COVID-19}

Differences between the two groups are summarized in Table 3. Patients with COVID-19 and in-hospital stroke onset had worse 90 days functional outcome (mRS 0-2 in $39 \%$ vs $69 \%$ of patients, $p: 0.05$ ) and not significantly higher mortality (39\% vs $15 \%, p$ : 0.38 ) compared with patients with out-of-hospital stroke onset (Fig. 1). Interestingly, when comparing patients with COVID-19 and out-of-hospital stroke onset with patients without COVID-19, the rate of good functional outcome (69\% vs 63\%, $p$ : 0.77 ) and mortality ( $15 \%$ vs $9 \%, p: 0.61)$ was similar. On the other hand, patients with COVID-19 and in-hospital stroke onset had significantly lower rate of good functional outcome (31\% vs $63 \%, p$ : 0.03$)$ and higher mortality ( $39 \%$ vs $9 \%, p<0.01)$ compared to patients without COVID-19. Furthermore, patients with in-hospital stroke onset had more commonly respiratory failure (69\% vs $15 \%, p$ : 0.05 ), ischemic complications ( $46 \%$ vs $7 \% ; p$ : 0.04$)$, higher NIHSS at stroke onset (median 16, IQR: $3.5-30.5$ vs 4 IQR: $2.5-11.0, p$ : 0.05), lower lymphocytic count $\left(0,88 \times 10^{3} / \mu \mathrm{L}\right.$ IQR: $0.67-1.20$ vs $1.54 \times 10^{3} / \mu \mathrm{L}$ IQR: $\left.1.16-1.91, p<0.01\right)$, and higher D-dimer $(15,316 \mathrm{mg} / \mathrm{dl}$ IQR: $1750-18,500 \mathrm{vs} 824 \mathrm{mg} / \mathrm{dl}$ IQR: 406-9281, $p$ : 0.02) compared with patients with outof-hospital stroke onset.

\section{Discussion}

The main finding of our study is that patients with COVID19 and out-of-hospital stroke onset fare a better outcome compared to patients with in-hospital stroke onset. Indeed, their outcome is like that of patients without COVID-19. Such findings confirm and extend those of a previous study showing that patients with in-hospital stroke had lower rate of discharge to home [8]. In our study, patients with in-hospital stroke onset tend to have higher NIHSS, higher D-dimer, and lower lymphocyte count compared to patients with in-hospital stroke onset. Such findings confirm those of Katz and colleagues [8] that in addition to D-dimer and lymphocyte abnormalities, showed higher level of white blood cells and CRP among patients with in-hospital stroke onset. In their study, patients with in-hospital stroke onset had more commonly multivessel involvement and higher risk of hemorrhagic transformation. We found a non-significantly increased rate of bilateral stroke among patients with out-ofhospital stroke onset but did not confirm the increased risk of hemorrhagic transformation.

The comparison of patients with stroke with and without COVID-19 yielded results in line with most of published studies $[7,10]$. We confirmed an increased mortality with higher rate of respiratory and thrombotic complications and markedly abnormal blood test among COVID-19 patients. We found lower rate of IVT or EVT in this population, confirming the results of a previous work [11]. It must be noted however that others $[12,13]$ have not reported this difference. Our finding can be explained by a lower chance of timely diagnosis among patients with severe COVID19 [2] and possibly longer workflow in the management of patients with stroke and COVID-19 reducing the chance of acute treatment. We also confirmed the higher rate of alterations of lymphocyte count, D-dimer, INR, fibrinogen, 
Table 1 Differences between patients with ischemic stroke with and without COVID-19

\begin{tabular}{|c|c|c|c|}
\hline & COVID-19 $(n=26)$ & Control $(n=111)$ & $p$ value \\
\hline Age (IQR) & $70.5(56.0-79.5)$ & $75.0(65.0-82.0)$ & 0.19 \\
\hline Female sex & $9(34.6 \%)$ & $45(40.5 \%)$ & 0.58 \\
\hline Etiology & & & $<0.01$ \\
\hline Cardioembolic & $11(42.3 \%)$ & $33(29.7 \%)$ & \\
\hline Atheroembolic & $1(3.8 \%)$ & $18(16.2 \%)$ & \\
\hline Lacunar & $2(7.7 \%)$ & $20(18.0 \%)$ & \\
\hline Other & $1(3.8 \%)$ & $6(5.4 \%)$ & \\
\hline More than one cause & $0(0.0 \%)$ & $2(1.8 \%)$ & \\
\hline ESUS † & $4(15.4 \%)$ & $32(28.8 \%)$ & \\
\hline Cryptogenic & $7(26.9 \%)$ & $0(0.0 \%)$ & \\
\hline Side of stroke & & & 0.97 \\
\hline Right & $10(38.5 \%)$ & $44(39.6 \%)$ & \\
\hline Left & $14(53.8 \%)$ & $60(54.1 \%)$ & \\
\hline Bilateral & $2(7.7 \%)$ & $7(6.3 \%)$ & \\
\hline Atrial fibrillation & $6(23.1 \%)$ & $34(30.6 \%)$ & 0.45 \\
\hline Diabetes mellitus & $6(23.1 \%)$ & $26(23.4 \%)$ & 0.97 \\
\hline Hypertension & $20(76.9 \%)$ & $75(67.6 \%)$ & 0.35 \\
\hline Dyslipidemia & $11(43.4 \%)$ & $43(38.7 \%)$ & 0.74 \\
\hline Coronary disease & $2(8.3 \%)$ & $16(14.4 \%)$ & 0.74 \\
\hline Previous stroke & $6(23.1 \%)$ & $13(11.7 \%)$ & 0.20 \\
\hline Previous antithrombotic treatment & & & 0.06 \\
\hline Antiplatelet & $4(15.4 \%)$ & $37(33.3 \%)$ & \\
\hline Anticoagulant & $5(19.2 \%)$ & $15(13.5 \%)$ & \\
\hline Both & $1(3.8 \%)$ & $0(0.0 \%)$ & \\
\hline Extracranial vessel occlusion & $1(4.3 \%)$ & $11(9.9 \%)$ & 0.69 \\
\hline Intracranial vessel occlusion & $13(52.0 \%)$ & $63(56.8 \%)$ & 0.67 \\
\hline $\mathrm{ICH}+$ & $6(23.1 \%)$ & $11(10.1 \%)$ & 0.10 \\
\hline Acute treatment & $7(26.9 \%)$ & $65(59.1 \%)$ & 0.02 \\
\hline IVT $\S$ & $3(11.5 \%)$ & $13(11.8 \%)$ & \\
\hline EVT II & $2(7.7 \%)$ & $32(29.1 \%)$ & \\
\hline $\mathrm{IVT}+\mathrm{EVT}$ & $2(7.7 \%)$ & $20(18.2 \%)$ & \\
\hline Mechanical Ventilation & $11(42.3 \%)$ & $3(2.7 \%)$ & $<0.01$ \\
\hline Pulmonary embolism & $6(26.1 \%)$ & $0(0.0 \%)$ & $<0.01$ \\
\hline Other ischemic events & $7(26.9 \%)$ & $0(0.0 \%)$ & $<0.01$ \\
\hline NIHSS $\dagger \dagger$ admission (IQR) & $6.5(3.0-20.0)$ & $7.0(4.0-15.0)$ & 0.67 \\
\hline NIHSS discharge (IQR) & $2.0(2.0-4.0)$ & $2.0(1.0-5.0)$ & 0.96 \\
\hline \multicolumn{4}{|l|}{ Blood tests } \\
\hline Glycaemia mg/dL (IQR) & $150.0(102.3-191.0)$ & $127.0(107.0-161.0)$ & 0.58 \\
\hline Lymphocytes $\times 10^{3} / \mu \mathrm{L}(\mathrm{IQR})$ & $1.19(0.83-1.62)$ & $1.55(1.09-1.95)$ & 0.02 \\
\hline $\mathrm{CRP} \neq \neq \mathrm{mg} / \mathrm{dL}(\mathrm{IQR})$ & $2.8(0.7-9.6)$ & $0.7(0.5-1.5)$ & $<0.01$ \\
\hline Creatinine mg/dL (IQR) & $0.81(0.62-1.20)$ & $0.87(0.76-1.08)$ & 0.47 \\
\hline INR (IQR) & $1.20(1.09-1.37)$ & $1.11(1.04-1.19)$ & 0.02 \\
\hline Platelets $\times 10^{3} / \mu \mathrm{L}(\mathrm{IQR})$ & $257.5(203.8-307.8)$ & $218.0(178.0-273.0)$ & 0.06 \\
\hline D-dimer mg/dL (IQR) & $2727.5(577.5-16,812.5)$ & $960.0(495.5-2328.5)$ & 0.01 \\
\hline Fibrinogen mg/dL (IQR) & $403.0(327.0-516.0)$ & $301.5(245.8-362.8)$ & $<0.01$ \\
\hline 90 days mortality & $7(26.9 \%)$ & $10(9.0 \%)$ & 0.02 \\
\hline 90 days good functional outcome & $13(50 \%)$ & $70(63.1 \%)$ & 0.22 \\
\hline
\end{tabular}

${ }^{\dagger}$ Embolic stroke of undetermined source; $\$$ Intracerebral hemorrhage; § Intravenous thrombolysis; II Endovascular thrombectomy; $\dagger \dagger$ National Institute of Health Stroke Scale; $\$$ - C-reactive protein 
Fig. 190 days functional outcome among patients with ischemic stroke with and without COVID-19 and among patients with COVID-19 and in-hospital stroke or out-ofhospital-stroke. The black boxes indicate a good functional outcome with modified Rankin Scale (mRS) 0 to 2
Table 2 Predictors of poor outcome (mRS 3-6) among patients with stroke and COVID-19

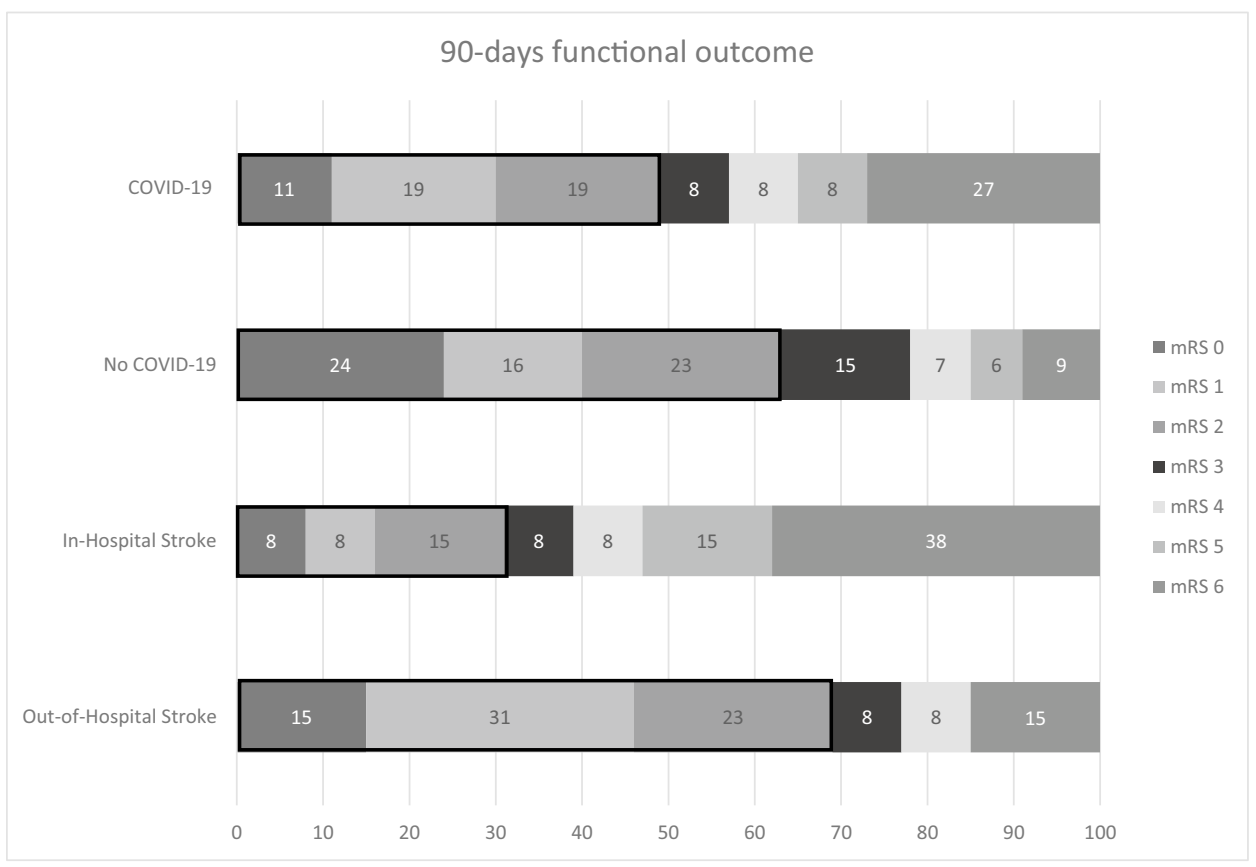

\begin{tabular}{|c|c|c|c|c|}
\hline & \multicolumn{2}{|l|}{ Univariate analysis } & \multicolumn{2}{|c|}{ Multivariate analysis } \\
\hline & OR (CI 95\%) & $p$ value & OR (CI 95\%) & $p$ value \\
\hline Age & $1.05(0.98-1.12)$ & 0.16 & & \\
\hline Female sex & $0.71(0.14-3.61)$ & 0.68 & & \\
\hline Acute treatment (IVT $\dagger ;$ EVT $\ddagger)$ & $0.29(0.05-1.90)$ & 0.20 & & \\
\hline NIHSS $\S$ & $1.22(1.05-1.41)$ & $<0.01$ & $1.11(0.91-1.36)$ & 0.31 \\
\hline ESUS $\llbracket /$ /cryptogenic stroke & $0.29(0.05-1.90)$ & 0.20 & & \\
\hline Lacunar stroke & $0.28(0.03-3.10)$ & 0.30 & & \\
\hline Atrial fibrillation & $7.50(0.73-76.77)$ & 0.09 & & \\
\hline Diabetes Mellitus & $2.44(0.36-16.55)$ & 0.36 & & \\
\hline Hypertension & $1.00(0.16-6.20)$ & 1.00 & & \\
\hline Dyslipidemia & $5.33(0.97-29.39)$ & 0.06 & & \\
\hline Glycaemia & $1.03(1.01-1.05)$ & 0.02 & $1.01(0.98-1.04)$ & 0.55 \\
\hline Lymphocytes & $0.01(0.00-0.40)$ & 0.01 & $0.02(0.00-2.01)$ & 0.10 \\
\hline $\mathrm{CRP} \dagger \dagger$ & $1.10(0.94-1.28)$ & 0.24 & & \\
\hline Creatinine & $7.17(0.63-81.5)$ & 0.11 & & \\
\hline INR & $3.72(0.03-519.69)$ & 0.60 & & \\
\hline Platelets & $1.00(0.99-1.01)$ & 0.94 & & \\
\hline D-dimer & $1.01(1.00-1.02)$ & $\mathbf{0 . 0 3}$ & $1.01(0.98-1.03)$ & 0.56 \\
\hline Fibrinogen & $1.00(0.99-1.00)$ & 0.27 & & \\
\hline SARS-CoV-2 pneumonia & $12.38(1.83-83.77)$ & 0.01 & & \\
\hline Pulmonary embolism & $3.67(0.51-26.22)$ & 0.20 & & \\
\hline In-hospital stroke & $5.06(0.96-26.78)$ & 0.06 & $0.39(0.01-14.81)$ & 0.61 \\
\hline
\end{tabular}

${ }^{\dagger}$ Intravenous thrombolysis; $\ddagger$ Endovascular thrombectomy; § National Institute of Health Stroke Scale; $\mathbb{1}$ Embolic stroke of undetermined source; $\dagger \dagger C$-reactive protein and CRP levels. Interestigly, at univariate analysis, higher D-dimer, lower lymphocyte count, higher glycaemia and higher NIHSS predicted a poor functional outcome among
COVID-19 patients. We did not find a significantly lower rate of good functional outcome among patients with COVID-19 compared to the control group. This is in contrast 
Table 3 Differences between patients with COVID-19 with in-hospital and out-of-hospital stroke onset

\begin{tabular}{|c|c|c|c|}
\hline & In-hospital stroke $(n=13)$ & Out-of-hospital stroke $(n=13)$ & p value \\
\hline Age (IQR) & $71.0(58.5-78.5)$ & $68.0(56.0-82.0)$ & 0.76 \\
\hline Female sex & $5(38.5 \%)$ & $4(30.8 \%)$ & 1.00 \\
\hline Etiology & & & 0.37 \\
\hline Cardioembolic & $6(46.2 \%)$ & $5(38.5 \%)$ & \\
\hline Atheroembolic & $0(0.0 \%)$ & $1(7.7 \%)$ & \\
\hline Lacunar & $0(0.0 \%)$ & $2(15.4 \%)$ & \\
\hline Other causes & $0(0.0 \%)$ & $1(7.7 \%)$ & \\
\hline More than one cause & $0(0.0 \%)$ & $0(0.0 \%)$ & \\
\hline ESUS $\dagger$ & $2(15.4 \%)$ & $2(15.4 \%)$ & \\
\hline Cryptogenic & $5(38.5 \%)$ & $2(15.4 \%)$ & \\
\hline Side of stroke & & & 0.14 \\
\hline Right & $3(23.1 \%)$ & $7(53.8 \%)$ & \\
\hline Left & $8(61.5 \%)$ & $6(46.2 \%)$ & \\
\hline Bilateral & $2(15.4 \%)$ & $0(0.0 \%)$ & \\
\hline Atrial fibrillation & $3(23.1 \%)$ & $3(23.1 \%)$ & 1.00 \\
\hline Diabetes Mellitus & $4(30.8 \%)$ & $2(15.4 \%)$ & 0.65 \\
\hline Hypertension & $8(61.5 \%)$ & $12(92.3 \%)$ & 0.16 \\
\hline Dyslipidemia & $6(46.2 \%)$ & $5(38.5 \%)$ & 0.69 \\
\hline Coronary disease & $2(15.4 \%)$ & $0(0 \%)$ & 0.48 \\
\hline Previous stoke & $1(7.7 \%)$ & $5(38.5 \%)$ & 0.16 \\
\hline Previous antithrombotic treatment & & & 0.53 \\
\hline Antiplatelet & $1(7.7 \%)$ & $3(23.1 \%)$ & \\
\hline Anticoagulant & $3(23.1 \%)$ & $2(15.4 \%)$ & \\
\hline Both & $1(7.7 \%)$ & $0(0.0 \%)$ & \\
\hline Extracranial vessel occlusion & $1(10.0 \%)$ & $0(0.0 \%)$ & 0.44 \\
\hline Intracranial vessel occlusion & $7(58.3 \%)$ & $6(46.2 \%)$ & 0.54 \\
\hline $\mathrm{ICH} \ddagger$ & $3(23.1 \%)$ & $3(23.1 \%)$ & 1.00 \\
\hline Treatment & $3(23.1 \%)$ & $4(31.8 \%)$ & 0.22 \\
\hline IVT $\S$ & $1(7.7 \%)$ & $2(15.4 \%)$ & \\
\hline EVT qI & $2(15.4 \%)$ & $0(0.0 \%)$ & \\
\hline Both & $0(0.0 \%)$ & $2(15.4 \%)$ & \\
\hline Mechanical ventilation & $9(69.2 \%)$ & $2(15.4 \%)$ & 0.05 \\
\hline Pulmonary embolism & $4(36.4 \%)$ & $2(16.7 \%)$ & 0.37 \\
\hline Other ischemic events & $6(46.2 \%)$ & $1(7.7 \%)$ & 0.04 \\
\hline NIHSS $\dagger \dagger$ admission (IQR) & $16.0(3.5-30.5)$ & $4.0(2.5-11.0)$ & 0.05 \\
\hline NIHSS discharge (IQR) & $2.0(2.0-2.0)$ & $3.0(2.0-4.0)$ & 0.32 \\
\hline \multicolumn{4}{|l|}{ Blood test } \\
\hline Glycaemia mg/dL (IQR) & $168.0(142.0-221.0)$ & $108.0(87.0-171.0)$ & 0.08 \\
\hline Lymphocytes $\times 10^{3} / \mu \mathrm{L}(\mathrm{IQR})$ & $0.88(0.67-1.20)$ & $1.54(1.16-1.91)$ & $<0.01$ \\
\hline $\mathrm{CRP} \neq+\mathrm{mg} / \mathrm{dL}(\mathrm{IQR})$ & $3.4(1.4-9.9)$ & $1.5(0.5-9.6)$ & 0.29 \\
\hline Creatinine mg/dL (IQR) & $0.72(0.60-1.33)$ & $0.92(0.65-1.23)$ & 0.62 \\
\hline INR (IQR) & $1.21(1.08-1.42)$ & $1.19(1.07-1.33)$ & 0.62 \\
\hline Platelets $\times 10^{3} / \mu \mathrm{L}(\mathrm{IQR})$ & $232.0(192.5-296.0)$ & $271.0(213.5-336.0)$ & 0.36 \\
\hline D-dimer mg/dL (IQR) & $15,316.0(1750.0-18,500.0)$ & $824.0(406.0-9281.0)$ & 0.02 \\
\hline Fibrinogen mg/dL (IQR) & $399.5(219.8-514.5)$ & $403.0(349.0-526.0)$ & 0.65 \\
\hline 90 days mortality & $5(38.5 \%)$ & $2(15.4 \%)$ & 0.38 \\
\hline 90 days good outcome & $4(30.8 \%)$ & $9(69.2 \%)$ & 0.05 \\
\hline
\end{tabular}

${ }^{\dagger}$ Embolic stroke of undetermined source; $\ddagger$ Intracerebral hemorrhage; § Intravenous thrombolysis; II Endovascular thrombectomy; $\dagger \dagger$ National Institute of Health Stroke Scale; $\$+C$-reactive protein 
with most of previous studies reporting a lower rate of discharge to home $[7,11]$ and a lower rate of functional independency at discharge $[12,14,15]$ among patients with stroke and COVID-19. Recently, however, Martí-Fàbregas and colleagues [16] reported results similar to ours. Our findings might be partially explained by the high percentage of patients with out-of-hospital stroke in our series (up to $50 \%$ ), faring a better outcome compared with patients with in-hospital stroke. The relatively low number of patients with COVID-19 in our series might have also hampered the possibility to show statistically significant differences.

Our study has many strengths. We analyzed 90 days functional outcome, whereas many of the previous cited studies analyzed the outcome at discharge. Very few patients were lost at follow-up. All patients admitted to our hospital were tested with a molecular swab for SARS-CoV2 infection, reducing the risk of false attribution to COVID-19 group or control group. Our control group was taken from the same period of the COVID-19 group reducing the risk of bias related to the observed reduced rate of minor stroke during COVID-19 pandemic [17]. Finally, we performed an accurate subgroup analysis comparing patients with COVID-19 in-hospital stroke and out-of-hospital stroke, highlighting important differences among these two groups. Our study has also some limitations: it is a retrospective study and bias is possible. The relatively low number of patients included reduced the statistical power of our study.

\section{Conclusions}

In our series, patients with COVID-19 and out-of-hospital stroke onset differ from patients with in-hospital stroke onset. They have milder stroke, do not show an alteration of coagulation tests, and fare a better outcome. Such findings might entail a different pathogenesis of stroke in these two groups and a possibly reduced importance of COVID-19-related coagulopathy in patients with out-of-hospital stroke onset. Considering that many studies are rising questions about the efficacy of IVT and EVT in patients with COVID$19[12,18]$, our findings, if confirmed and extended, might also be important from a therapeutic point of view. In fact, patients with out-of-hospital stroke might also present a better response to acute stroke treatment.

Supplementary Information The online version contains supplementary material available at https://doi.org/10.1007/s10072-021-05807-w.

Author contribution All authors contributed to the study conception and design. Data collection and analysis were performed by Ludovico Ciolli, Veronica Righi, Stefania Maffei, Gabriele Vandelli, Laura Giacobazzi, Niccolò Biagioli, and Donato Marzullo. The first draft of the manuscript was written by Ludovico Ciolli and all authors commented on previous versions of the manuscript. All authors read and approved the final manuscript.

The authors have stated explicitly that there are no conflicts of interest in connection with this article. This research received no specific grant from any funding agency in the public, commercial or not-forprofit sectors. Our ethic committee waived the need of informed consent considering the retrospective nature of our study. The data that support the findings of this study are available from the corresponding author upon reasonable request.

\section{References}

1. Mao L, Jin H, Wang M, Hu Y, Chen S, He Q, Chang J, Hong C, Zhou Y, Wang D, Miao X, Li Y, Hu B (2020) Neurologic manifestations of hospitalized patients with coronavirus disease 2019 in Wuhan. China JAMA Neurol 77(6):683-690. https://doi.org/ 10.1001/jamaneurol.2020.1127 (PMID: 32275288)

2. Bigliardi G, Ciolli L, Giovannini G, Vandelli L, Dell'Acqua ML, Borzì GM, Picchetto L, Rosafio F, Ricceri R, Meletti S (2020) Middle cerebral artery ischemic stroke and COVID-19: a case report. J Neurovirol 26(6):967-969. https://doi.org/10.1007/ s13365-020-00898-1 (PMID: 32901391)

3. Fridman S, Bres Bullrich M, Jimenez-Ruiz A, Costantini P, Shah P, Just C, Vela-Duarte D, Linfante I, Sharifi-Razavi A, Karimi N, Bagur R, Debicki DB, Gofton TE, Steven DA, Sposato LA (2020) Stroke risk, phenotypes, and death in COVID-19: systematic review and newly reported cases. Neurology 95(24):e3373e3385. https://doi.org/10.1212/WNL.0000000000010851 (PMID: 32934172)

4. Smilowitz NR, Subashchandran V, Yuriditsky E, Horowitz JM, Reynolds HR, Hochman JS, Berger JS (2021) Thrombosis in hospitalized patients with viral respiratory infections versus COVID19. Am Heart J 231:93-95. https://doi.org/10.1016/j.ahj.2020.10. 075 (PMID: 33181067)

5. Spence JD, de Freitas GR, Pettigrew LC, Ay H, Liebeskind DS, Kase CS, Del Brutto OH, Hankey GJ, Venketasubramanian N (2020) Mechanisms of stroke in COVID-19. Cerebrovasc Dis 49(4):451-458. https://doi.org/10.1159/000509581 (PMID: 32690850)

6. Ramos-Araque ME, Siegler JE, Ribo M, Requena M, López C, de Lera M, Arenillas JF, Pérez IH, Gómez-Vicente B, Talavera B, Portela PC, Guillen AN, Urra X, Llull L, Renú A, Nguyen TN, Jillella D, Nahab F, Nogueira R, Haussen D, Then R, Thon JM, Esparragoza LR, Hernández-Pérez M, Bustamante A, Mansour OY, Megahed M, Hassan T, Liebeskind DS, Hassan A, Bushnaq S, Osman M, Vazquez AR (2021) SVIN Multinational Registry and Task Force. Stroke etiologies in patients with COVID-19: the SVIN COVID-19 multinational registry. BMC Neurol 21(1):43. https://doi.org/10.1186/s12883-021-02075-1 (PMID: 33514335)

7. Dhamoon MS, Thaler A, Gururangan K, Kohli A, Sisniega D, Wheelwright D, Mensching C, Fifi JT, Fara MG, Jette N, Cohen E, Dave P, DiRisio AC, Goldstein J, Loebel EM, Mayman NA, Sharma A, Thomas DS, Vega Perez RD, Weingarten MR, Wen HH, Tuhrim S, Stein LK (2021) Mount Sinai Stroke Investigators*. Acute cerebrovascular events with COVID-19 infection. Stroke. 52(1):48-56. https://doi.org/10.1161/STROKEAHA.120. 031668 (PMID: 33280551)

8. Katz JM, Libman RB, Wang JJ, Filippi CG, Sanelli P, Zlochower A, Gribko M, Pacia SV, Kuzniecky RI, Najjar S, Azhar S (2021) COVID-19 Severity and Stroke: Correlation of Imaging and Laboratory Markers. AJNR Am J Neuroradiol 42(2):257-261. https:// doi.org/10.3174/ajnr.A6920 (PMID: 33122216)

9. Adams HP Jr, Bendixen BH, Kappelle LJ, Biller J, Love BB, Gordon DL, Marsh EE 3rd (1993) Classification of subtype of acute 
ischemic stroke. Definitions for use in a multicenter clinical trial. TOAST. Trial of Org 10172 in Acute Stroke Treatment. Stroke. 24(1):35-41. https://doi.org/10.1161/01.str.24.1.35 (PMID: 7678184)

10. Perry RJ, Smith CJ, Roffe C, Simister R, Narayanamoorthi S, Marigold R, Willmot M, Dixit A, Hassan A, Quinn TJ, Ankolekar S, Zhang L, Banerjee S, Ahmed U, Padmanabhan N, Ferdinand P, McGrane F, Banaras A, Marks IH, Werring DJ, SETICOS collaborators (2021) Characteristics and outcomes of COVID-19 associated stroke: a UK multicentre case-control study. J Neurol Neurosurg Psychiatry 92(3):242-248. https://doi.org/10.1136/ jnnp-2020-324927 (PMID: 33154179)

11. de Havenon A, Ney JP, Callaghan B, Delic A, Hohmann S, Shippey E, Esper GJ, Stulberg E, Tirschwell D, Frontera J, Yaghi S, Anadani M, Majersik JJ (2021) Impact of COVID-19 on outcomes in ischemic stroke patients in the United States. J Stroke Cerebrovasc Dis 30(2):105535. https://doi.org/10.1016/j.jstro kecerebrovasdis.2020.105535 (PMID: 33310595)

12. Fuentes $B$, Alonso de Leciñana $M$, García-Madrona S, Díaz-Otero F, Aguirre C, Calleja P, Egido JA, Carneado-Ruiz J, Ruiz-Ares G, Rodríguez-Pardo J, Rodríguez-López Á, Ximénez-Carrillo Á, de Felipe A, Ostos F, González-Ortega G, Simal P, Gómez Escalonilla CI, Gómez-Porro-Sánchez P, Desanvicente Z, Reig G, Gil-Núñez A, Masjuán J, Díez-Tejedor E (2021) Stroke acute management and outcomes during the COVID-19 outbreak: a cohort study from the madrid stroke network. Stroke. 52(2):552562. https://doi.org/10.1161/STROKEAHA.120.031769 (Epub 2021 Jan 7. PMID: 33406872)

13. Yaghi S, Ishida K, Torres J, Mac Grory B, Raz E, Humbert K, Henninger N, Trivedi T, Lillemoe K, Alam S, Sanger M, Kim S, Scher E, Dehkharghani S, Wachs M, Tanweer O, Volpicelli F, Bosworth B, Lord A, Frontera J (2020) SARS-CoV-2 and Stroke in a New York Healthcare System. Stroke 51(7):2002-2011. https://doi.org/10.1161/STROKEAHA.120.030335 (PMID: 32432996)

14. Akhtar N, Abid FB, Kamran S, Singh R, Imam Y, AlJerdi S, AlMaslamani M, Shuaib A (2021) Characteristics and comparison of 32 COVID-19 and non-COVID-19 ischemic strokes and historical stroke patients. J Stroke Cerebrovasc Dis 30(1):105435. https://doi.org/10.1016/j.jstrokecerebrovasdis.2020.105435 (PMID: 33171425)

15. Srivastava PK, Zhang S, Xian Y, Xu H, Rutan C, Alger HM, Walchok J, Williams J, de Lemos JA, Decker-Palmer MR, Alhanti B, Elkind MSV, Messé SR, Smith EE, Schwamm LH, Fonarow GC (2021) Acute ischemic stroke in patients with COVID-19: an analysis from get with the guidelines-stroke. Stroke 52(5):18261829. https://doi.org/10.1161/STROKEAHA.121.034301 (PMID: 33728926)

16. Martí-Fàbregas J, Guisado-Alonso D, Delgado-Mederos R, Martínez-Domeño A, Prats-Sánchez L, Guasch-Jiménez M, Cardona P, Núñez-Guillén A, Requena M, Rubiera M, Olivé M, Bustamante A, Gomis M, Amaro S, Llull L, Ustrell X, Castilho de Oliveira G, Seró L, Gomez-Choco M, Mena L, Serena J, Bashir Viturro S, Purroy F, Vicente M, Rodríguez-Campello A, Ois A, Catena E, Carmen Garcia-Carreira M, Barrachina O, Palomeras E, Krupinski J, Almeria M, Zaragoza J, Esteve P, Cocho D, Moreira A, van Eendenburg C, Emilio Codas J, Pérez de la Ossa N, Salvat M, Camps-Renom P (2021) Impact of COVID-19 infection on the outcome of patients with ischemic stroke. Stroke. STROKEAHA121034883. https://doi.org/10.1161/STROK EAHA.121.034883. PMID: 34455823

17 Aguiar de Sousa D, Sandset EC, Elkind MSV (2020) The curious case of the missing strokes during the COVID-19 pandemic. Stroke 51(7):1921-1923. https://doi.org/10.1161/STROKEAHA. 120.030792 (PMID: 32466737)

18. Cagnazzo F, Piotin M, Escalard S, Maier B, Ribo M, Requena M, Pop R, Hasiu A, Gasparotti R, Mardighian D, Piano M, Cervo A, Eker OF, Durous V, Sourour NA, Elhorany M, Zini A, Simonetti L, Marcheselli S, Paolo NN, Houdart E, Guédon A, Ligot N, Mine B, Consoli A, Lapergue B, Cordona Portela P, Urra X, Rodriguez A, Bolognini F, Lebedinsky PA, Pasco-Papon A, Godard S, Marnat G, Sibon I, Limbucci N, Nencini P, Nappini S, Saia V, Caldiera V, Romano D, Frauenfelder G, Gallesio I, Gola G, Menozzi R, Genovese A, Terrana A, Giorgianni A, Cappellari M, Augelli R, Invernizzi P, Pavia M, Lafe E, Cavallini A, Giossi A, Besana M, Valvassori L, Macera A, Castellan L, Salsano G, Di Caterino F, Biondi A, Arquizan C, Lebreuche J, Galvano G, Cannella A, Cosottini M, Lazzarotti G, Guizzardi G, Stecco A, Tassi R, Bracco S, Bianchini E, Micieli C, Pascarella R, Napoli M, Causin F, Desal H, Cotton F, Costalat V (2021) ET-COVID-19 Study Group*. European Multicenter Study of ET-COVID-19. Stroke 52(1):31-39. https://doi.org/10.1161/STROKEAHA.120. 031514 (PMID: 33222617)

Publisher's Note Springer Nature remains neutral with regard to jurisdictional claims in published maps and institutional affiliations. 